\title{
Sorption-Desorption Behaviour of Barium on Clays*
}

\author{
C. Eylem, ${ }^{a, b}$ H. N. Erten, ${ }^{a \ddagger}$ H. Göktürk ${ }^{b}$ \\ ${ }^{a}$ Department of Chemistry, Bilkent University, POB 8, 06572 Maltepe, Ankara, Turkey \\ ${ }^{b}$ Department of Chemistry, Middle East Technical University, Ankara, Turkey \\ (Received 8 February 1989; revised version received 6 July 1989 ; \\ accepted 7 July 1989)
}

\begin{abstract}
Batch experiments were performed to study the sorption behaviour of $B \mathrm{a}^{2+}$ ion on three different clay minerals determined to be predominantly kaolinite, montmorillonite and mixed chlorite-illite. Synthetic groundwater was used and the concentration of $\mathrm{Ba}^{2+}$ ion was in the range of $10^{-8}$ to $10^{-4} \mathrm{~N}$. Grain sizes of the solid particles were all $<38 \mu \mathrm{m}$. Cation exchange capacities were obtained using the silver-thiourea (AgTU) method. The variation of $\mathrm{R}_{\mathrm{D}}$ values was studied as a function of contact time, shaking rate, $\mathrm{Ba}^{2+}$ ion concentration, $\mathrm{v} / \mathrm{m}$ ratio and $\mathrm{pH}$. The saturation time varied with each type of clay; about 6,8 and 12 days of shaking time were necessary for chlorite-illite mixed clay, kaolinite and montmorillonite respectively. Shaking rate affected only the rate of sorption and not the saturaton $\mathrm{R}_{\mathrm{D}}$ values. Sorption was found to be reversible on kaolinite and partly reversible on montmorillonite and chlorite-illite clays. The variation of $\mathrm{R}_{\mathrm{D}}$ as a function of $\mathrm{Ba}^{2+}$ ion concentration exhibited characteristic inverse $S$-shaped curves suggesting the presence of at least two different types of exchange sites. Sorption of $\mathrm{Ba}^{2+}$ ion was observed to depend on $\mathrm{pH}$ and $\mathrm{v} / \mathrm{m}$ ratio. The sorption isotherms were found to fit Freundlich and Dubinin-Radushkevich type isotherms well.
\end{abstract}

\section{INTRODUCTION}

Disposal of nuclear wastes in geologic media is believed to be an adequate way of providing the necessary protection for humans and the environ-

* Supported in part by the International Atomic Energy Agency, Vienna and by the Turkish Atomic Energy Authority, Ankara.

${ }^{\ddagger}$ To whom correspondence should be addressed.

183

J. Environ. Radioactivity 0265-931X/90/\$03.50 (C) 1990 Elsevier Science Publishers Ltd, England. Printed in Great Britain 
ment. Since sorption in geologic media is an important mechanism for the delay of radionuclide migration to the biosphere and the food chain, sorption and desorption characteristics of radionuclides should be investigated in order to estimate rates of transport of the nuclides in the event of water penetration into and through the waste repository. Possible mechanisms in rock-nuclide interactions are physical sorption, chemisorption, ion-exchange, precipitation, substitutions of ions in the crystal lattice and diffusion into the rock matrix followed by sorption in the solid. These mechanisms differ in kinetics, reversibility, $\mathrm{pH}$-dependence, etc. Thus, various chemical and physical parameters would have a large influence on the sorption of a radionuclide on a solid. Because clays have been proposed as suitable backfill materials for the storage of radioactive waste, there has been an increasing interest in the studies of sorption behaviour of various radionuclides on clays (Torstenfelt et al., 1981; Grütter et al., 1986; Torstenfelt, 1986; Berry et al., 1988).

Our previous work on sorption has been concerned with the fission products cesium and strontium (Erten et al., 1988a; Erten et al., 1988b). Surveying the literature on the subject, it appears that the sorption of barium has not been extensively studied. We have therefore decided to investigate the sorption behaviour of barium on clays. ${ }^{140} \mathrm{Ba}\left(t_{1 / 2}=12 \cdot 8 \mathrm{~d}\right)$ is a serious radiocontaminant during the first 100 days when fission products are discharged into the environment from sources such as nuclear power plants (routinely or accidentally) and from nuclear weapons testing. Furthermore, $\mathrm{Ba}^{2+}$ lies between $\mathrm{Sr}^{2+}$ and $\mathrm{Ra}^{2+}$ which are the most interesting nuclides of Group $2 \mathrm{~A}$ with respect to radioactive waste considerations. Therefore, as a representative of the alkali-earth homologs, barium is a suitable element to study. ${ }^{133} \mathrm{Ba}$ was chosen as a tracer because of its long half-life (10.7 year) and well observable $\gamma$-ray $356 \mathrm{keV}$ energy.

\section{EXPERIMENTAL}

\section{Clay minerals}

Clay minerals from three regions of Turkey, Sindırg1, Giresun and Afyon, were used in the $\mathrm{Ba}^{2+}$ ion sorption studies. X-ray diffraction analysis and infrared spectrometry were used for identification. The X-ray patterns as shown in Fig. 1 indicated that the clays were predominantly of kaolinite, montmorillonite and chlorite-illite types. Size fractionation of the minerals was accomplished by sieving and sedimentation (Loomis, 1938; Norton \& Speil, 1938). Montmorillonite and kaolinite clays were separated into three different grain sizes, $<5 \mu \mathrm{m}, 5-10 \mu \mathrm{m}$ and $10-30 \mu \mathrm{m}$. A natural 


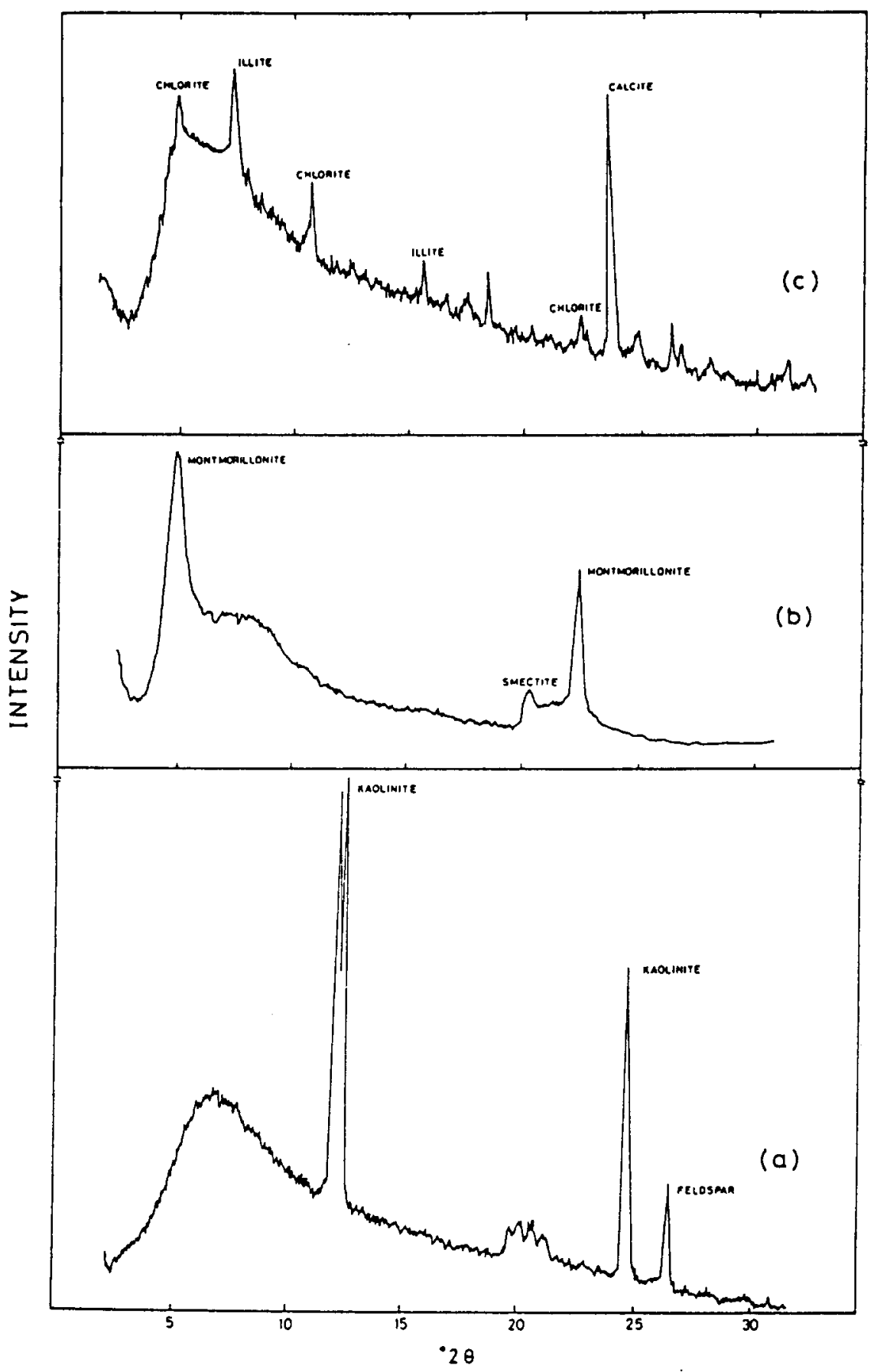

Fig. 1. X-ray diffraction spectra of clay samples (CuK $\mathrm{Cadiation}_{\alpha}$ : (a) Sındırgı clay; (b) Giresun clay; (c) Afyon clay. 
mineral sample containing mainly chlorite-illite mixed clay was not a pure sample. It was passed only through a $38 \mu \mathrm{m}$ sieve and was used without further fractionation. Cation exchange capacities (CEC) of the clay minerals were determined by measuring the silver remaining in solution after silver-thiourea (AgTU) extraction (Searle, 1986).

TABLE 1

Chemical Composition of Synthetic Groundwater Samples Used in the Sorption Studies

\begin{tabular}{lccc}
\hline \multicolumn{1}{c}{ Component (meq/l) } & Sindirgi & Giresun & Afyon \\
\hline $\mathrm{Na}^{+}$ & $0 \cdot 89^{a}$ & $0 \cdot 22$ & $2 \cdot 08$ \\
$\mathrm{~K}^{+}$ & - & $0 \cdot 01$ & $0 \cdot 40$ \\
$\mathrm{Ca}^{2+}$ & $4 \cdot 70$ & $2 \cdot 28$ & $5 \cdot 46$ \\
$\mathrm{Mg}^{2+}$ & $3 \cdot 15$ & $0 \cdot 30$ & $3 \cdot 38$ \\
$\mathrm{CO}_{3}^{2-b}$ & $0 \cdot 17$ & $0 \cdot 28$ & $0 \cdot 90$ \\
$\mathrm{NO}_{3}^{-}$ & $3 \cdot 14$ & $1 \cdot 34$ & $4 \cdot 48$ \\
$\mathrm{Cl}^{-}$ & $0 \cdot 84$ & $0 \cdot 02$ & $0 \cdot 25$ \\
$\mathrm{SO}_{4}^{2-b}$ & $0 \cdot 18$ & $0 \cdot 10$ & $0 \cdot 82$ \\
$\mathrm{pH}^{-6}$ & $7 \cdot 2$ & $6 \cdot 5$ & $7 \cdot 1$ \\
\hline
\end{tabular}

${ }^{a} \mathrm{Na}^{+}+\mathrm{K}^{+}$concentration.

${ }^{b}$ Carbonate and sulphate were replaced by nitrate when sorption studies were carried out at higher initial $\mathrm{Ba}^{2+}$ ion concentration.

\section{Synthetic groundwater}

Synthetic groundwaters having similar compositions to the groundwaters of the three regions were used in sorption experiments. Bicarbonate ions, however, were largely replaced by nitrate ions in order to prevent carbonate precipitation. Table 1 gives the synthetic groundwater compositions used in the sorption studies.

\section{Procedure}

The sorption experiments were carried out using the batch technique. Weighed amounts of clay samples were kept in contact with known volumes of solution for certain times. Polypropylene centrifuge tubes with caps were used throughout. A typical sorption experiment employed approximately $50 \mathrm{mg}$ clay (dry weight) and $4 \mathrm{ml}$ solution resulting in a liquid-solid ratio of $80 \mathrm{ml} / \mathrm{g}$. The samples were shaken at room temperature using a circular type shaker with a speed of $190 \mathrm{rpm}$. Phase separations were achieved by centrifuging at a speed of $12000 \mathrm{rpm}$ for about 30 minutes. 
${ }^{133} \mathrm{Ba}\left(t_{1 / 2}=10.7\right.$ year $)$ purchased from the Radiochemical Center, Amersham was used as tracer. Activity measurements were made by means of a $\mathrm{NaI}(\mathrm{Tl})$ detector.

In the pretreatment step, clays were equilibrated with the synthetic groundwater. The concentrations of the major cations and the $\mathrm{pH}$ of the pretreatment solution changed only slightly during this step.

At the beginning of the sorption step, synthetic groundwater containing ${ }^{133} \mathrm{Ba}$ was added to the samples. Barium concentrations between $1.56 \times 10^{-8} \mathrm{~N}$ and $1.53 \times 10^{-3} \mathrm{~N}$ were used. The sorption time varied from 1 hour to 28 days. In the desorption studies, Ba-free synthetic groundwater was used following the adsorption step.

\section{Concentration and distribution ratio calculations}

The distribution ratio is defined as:

$$
R_{D, a d}=\frac{[\mathrm{Ba}]_{s, a d}}{[\mathrm{Ba}]_{a d}}
$$

where $[\mathrm{Ba}]_{s . a d}=$ concentration of barium in the solid phase after sorption $(\mathrm{meq} / \mathrm{g})$ and $[\mathrm{Ba}]_{a d}=$ concentration of barium in the solution after sorption $(\mathrm{meq} / \mathrm{ml})$.

Since at the beginning of the sorption step $V(\mathrm{ml})$ of solution with concentration $[\mathrm{Ba}]^{0}$ is added and at the end of the sorption step $\left(V+\Delta W_{p t}\right)$ $\mathrm{ml}$ of solution with concentration $[\mathrm{Ba}]_{a d}$ are present, the concentration of $\mathrm{Ba}$ in the solid phase after sorption is given by:

$$
[\mathrm{Ba}]_{s, a d}=\frac{V[\mathrm{Ba}]^{0}-[\mathrm{Ba}]_{a d}\left(V+\Delta W_{p t}\right)}{W_{s}}
$$

$[\mathrm{Ba}]_{a d}$ may be defined in terms of activity as

$$
[\mathrm{Ba}]_{a d}=\frac{A_{1, a d}}{A^{0}}[\mathrm{Ba}]^{0}
$$

From eqns (1), (2) and (3) the following equation is obtained:

$$
R_{D, a d}=\frac{V A^{0}-A_{1, a d}\left(V+\Delta W_{p t}\right)}{A_{1, a d} W_{s}}
$$

Here, $A^{0}=$ initial count rate of solution added for sorption (cps); 
$A_{1, a d}=$ count rate of solution after sorption (cps); $W_{s}=$ weight of solid material (g); $V=$ volume of solution (ml); and $\Delta W_{p t}=$ amount of liquid remaining in the tube after pretreatment, before sorption $(\mathrm{g})$.

For desorption studies, using similar equations as above, the following relation for the distribution ratio is derived;

$$
R_{D, d e}=\frac{V A^{0}-A_{1, a d}\left(V+\Delta W_{p t}-\Delta W_{a d}\right)-A_{1, d e}\left(V+\Delta W_{a d}\right)}{A_{1, d e} W_{s}}
$$

where, $\Delta W_{a d}=$ the amount of liquid remaining in the tube after sorption and decantation (g); and $A_{1, d e}=$ count rate of solution after desorption (cps).

\section{RESULTS AND DISCUSSION}

The particle size distributions of the three clay minerals were obtained by the Andreasen pipette method (Loomis, 1938; Norton \& Speil, 1938) and are shown in Fig. 2. Kaolinite type clay is seen to have the highest fraction of smaller size particles.

CEC values, determined experimentally via the AgTU complex, were also calculated from the Dubinin-Radushkevich isotherm model. The results are shown in Table 2 together with the literature values. The CEC values of kaolinite and chlorite-illite type clays are in very good agreement

TABLE 2

Cation Exchange Capacities of the Clay Minerals Used for $\mathrm{Ba}^{2+}$ Sorption Studies

\begin{tabular}{lcccc}
\hline \multirow{2}{*}{ Clay } & \multicolumn{4}{c}{$C E C($ meq $/ 100 \mathrm{~g})$} \\
\cline { 2 - 5 } & $d(\mu \mathrm{m})$ & Literature $^{-}$ & Experimental $^{a}$ & Model $^{b}$ \\
\hline Kaolinite & $<5$ & & 5 & 4 \\
& $5-10$ & $3-15$ & 9 & 9 \\
Montmorillonite & $10-30$ & & 5 & 4 \\
& $<5$ & & 22 & 22 \\
& $5-10$ & $70-100$ & 21 & 21 \\
Chlorite-illite & $10-30$ & & 19 & 21 \\
\hline
\end{tabular}

${ }^{a}$ Determined experimentally using the Silver-Thiourea method.

${ }^{b}$ Calculated from the Dubinin-Radushkevich isotherm model. 


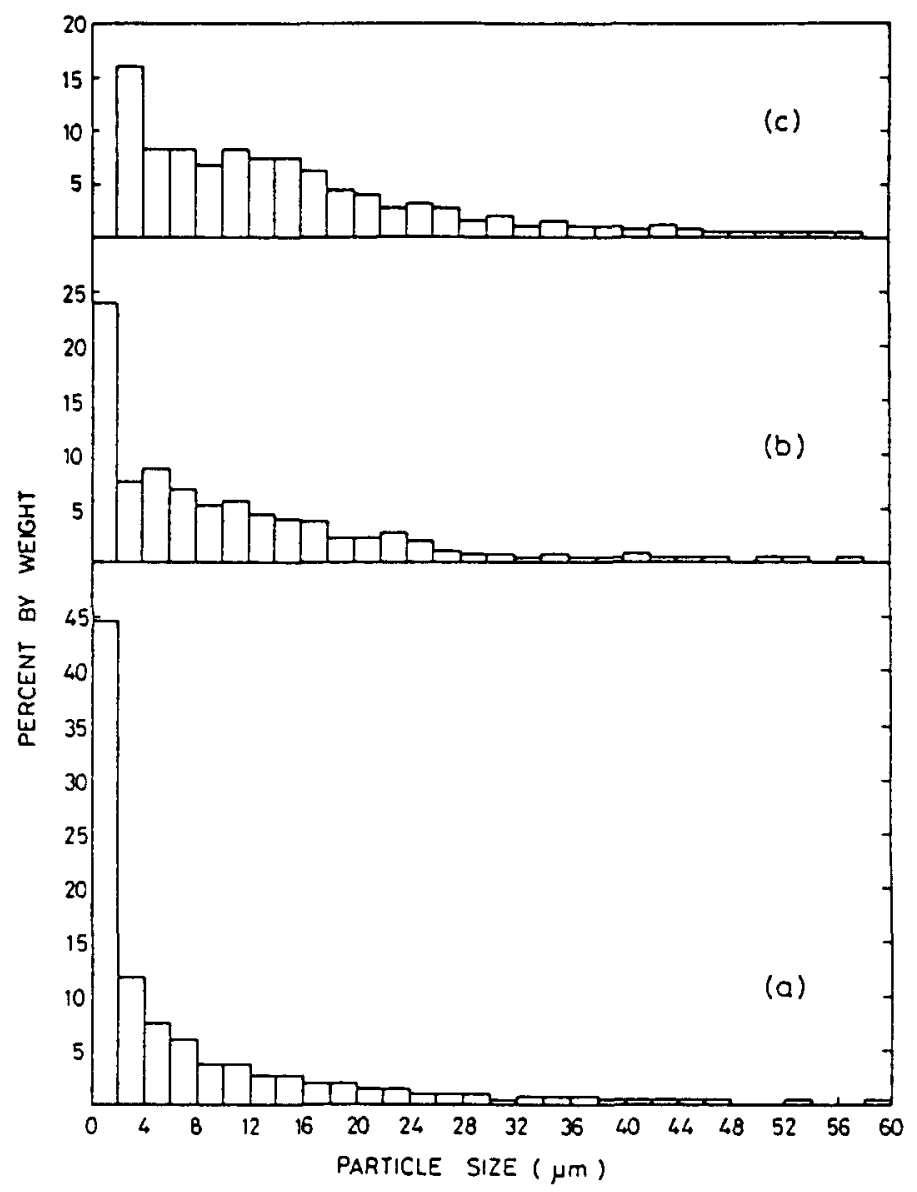

Fig. 2. Size distributions of clay samples. Per cent by weight against particle size: (a) Sindirgı clay; (b) Giresun clay; (c) Afyon clay.

with the literature data, whereas those for montmorillonite differ considerably. This probably reflects the CEC method used, silver-thiourea being a bulky complex and hence unable to exchange with the cations present between the layers in montmorillonite-like clays, for which the ion exchange capacity is mostly determined by the cations present at the sites located along the interlattice layers. Cremers et al. (1988) used the AgTU complex method in order to analyse quantitatively the number and selectivity pattern of different sites in various clay minerals, by masking these sites on the crystal edges using AgTU and letting ion exchange take place only at the sites located between layers. 


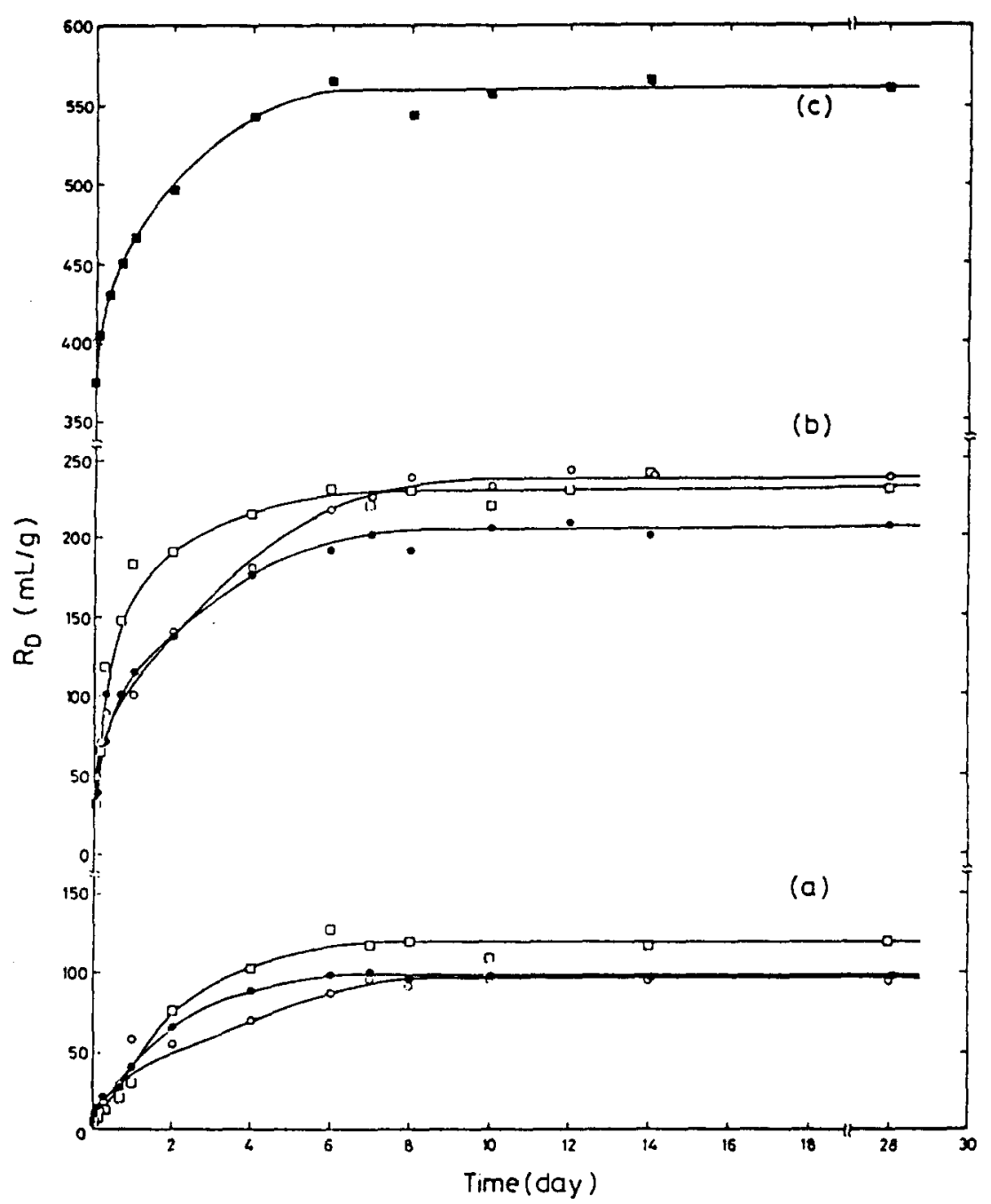

Fig. 3. Sorption kinetics. Change of $R_{D}$ with contact time (initial $\mathrm{Ba}^{2+}$ ion concentration $=1.56 \times 10^{-8} \mathrm{meq} / \mathrm{ml}$ ). (a) Kaolinite particle size: $0,<5 \times 10^{-6} \mathrm{~m} ; \square$, $5-10 \times 10^{-6} \mathrm{~m} ; 0,10-30 \times 10^{-6} \mathrm{~m}$. (b) Montmorillonite particle size: $\bigcirc,<5 \times 10^{-6} \mathrm{~m} ; \square$, $5-10 \times 10^{-6} \mathrm{~m} ; 0,10-30 \times 10^{-6} \mathrm{~m}$. (c) Chlorite-illite mixed clay particle size: $\square$, $<38 \times 10^{-6} \mathrm{~m}$.

\section{Kinetic studies}

Kinetic studies were performed using two $\mathrm{Ba}^{2+}$ concentrations, $1.56 \times 10^{-8} \mathrm{~N}$ and $1.53 \times 10^{-5} \mathrm{~N}$ and various grain sizes. The results are shown in Fig. 3. It is observed that saturation is achieved at 6,8 and 10 days of shaking for chlorite-illite mixed clay, kaolinite and montmorillonite 


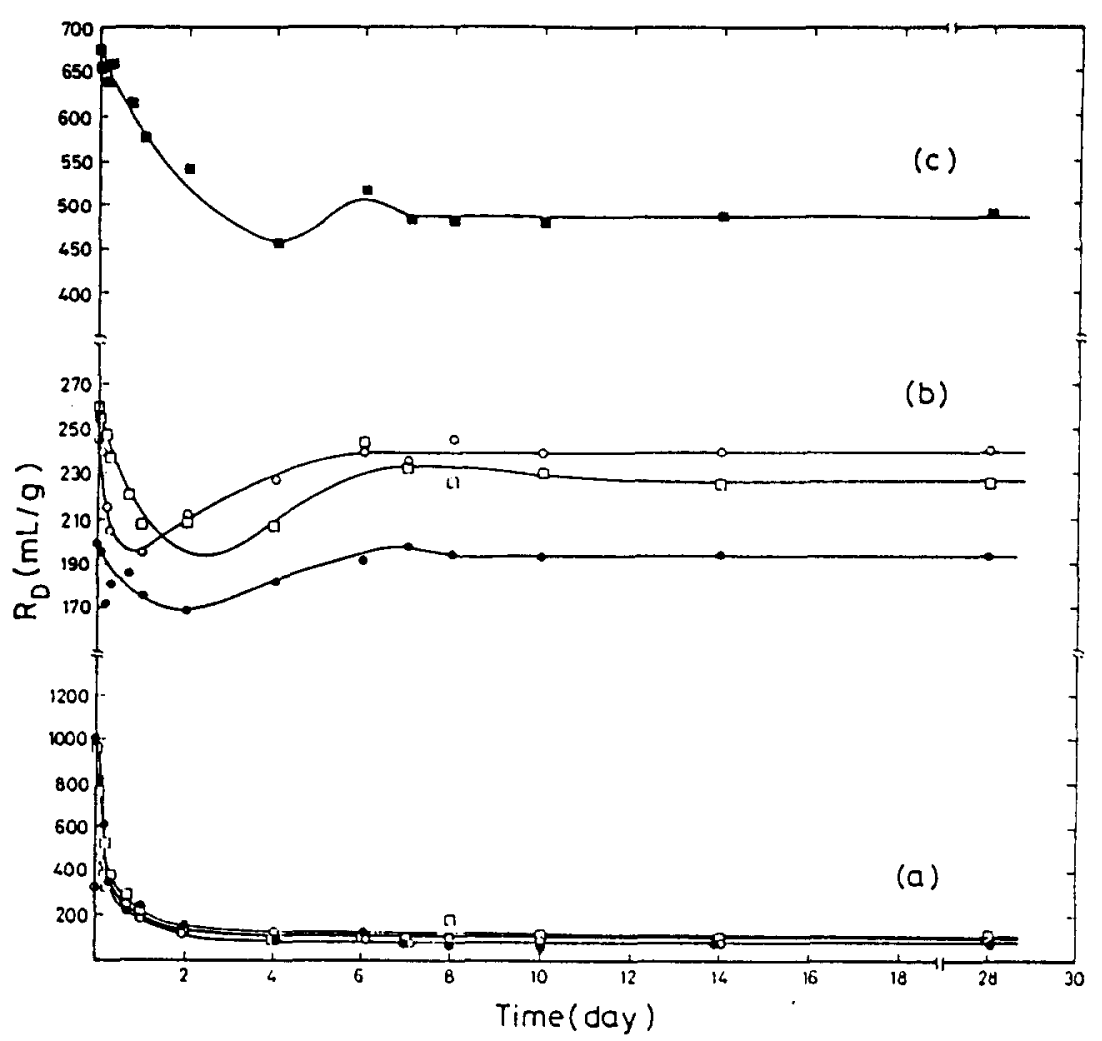

Fig. 4. Desorption kinetics. Change of $R_{D}$ with contact time (initial $\mathrm{Ba}^{2+}$ ion concentration $=1.56 \times 10^{-8} \mathrm{meq} / \mathrm{ml}$ ). (a) Kaolinite particle size: $0,<5 \times 10^{-6} \mathrm{~m} ; \square$. $5-10 \times 10^{-6} \mathrm{~m} ; 0,10-30 \times 10^{-6} \mathrm{~m}$. (b) Montmorillonite particle size: $0,<5 \times 10^{-6} \mathrm{~m} ; \square$. $5-10 \times 10^{-6} \mathrm{~m} ; 0,10-30 \times 10^{-6} \mathrm{~m}$. (c) Chlorite-illite mixed clay particle size: $<38 \times 10^{-6} \mathrm{~m}$.

respectively. The ion exchange properties of kaolinite are generally believed to reflect broken bonds and possibly $\mathrm{OH}$ bonds on the surface of the clay particles (Carroll, 1959). It was thus expected that distribution ratios for kaolinite would exhibit a dependence on the particle size, as was previously observed with $\mathrm{Cs}^{+}$and $\mathrm{Si}^{2+}$ cations in our studies (Erten et al., $1988 a$; Erten et al., 1988b). However, such a strong dependence was not observed. On the other hand, montmorillonite had higher $R_{D}$ values at smaller grain sizes, indicating surface area dependence. In the case of chlorite-illite mixed clay, since the percentage of small particles was markedly low (Fig. 2), sorption experiments were performed using unseparated grains. The desorption kinetic studies, as illustrated in Fig. 4, indicate rapid initial desorption for all clay types, followed by readsorption until saturation for montmorillonite. 


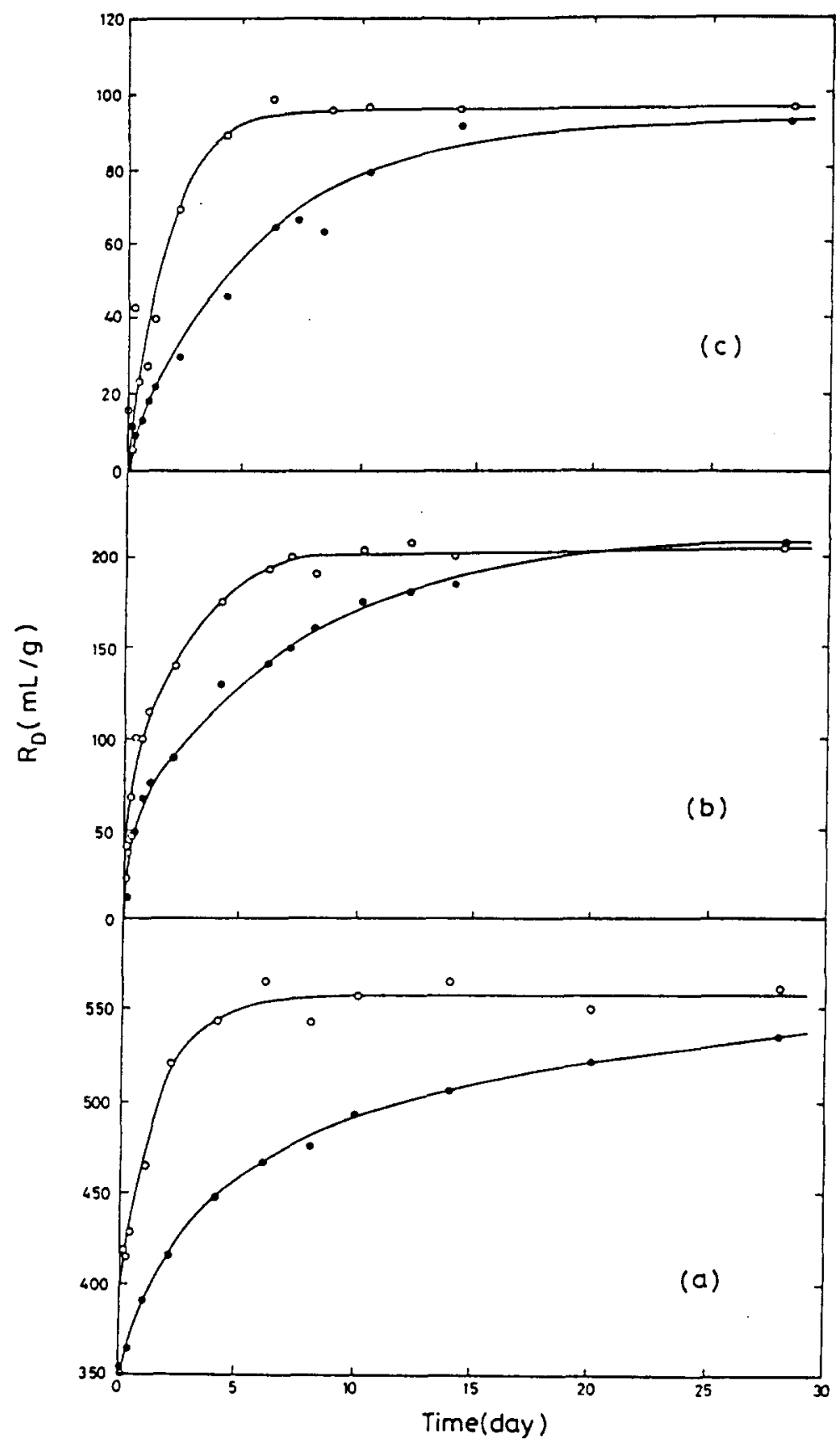

Fig. 5. Sorption kinetics. Variation of $R_{D}$ as a function of time (initial $\mathrm{Ba}^{2+}$ ion concentration $=1.56 \times 10^{-8} \mathrm{meq} / \mathrm{ml}$ ): (a) chlorite-illite mixed clay; (b) montmorillonite; (c) kaolinite. $\bigcirc$, Samples were shaken at a rate of $190 \mathrm{rpm}$; samples were not shaken. 
In order to investigate the effect of water composition on sorption, pretreatment water was used in studying the sorption kinetics of kaolinite. Almost the same $R_{D}$ values were obtained with pretreatment water as with synthetic water. Equilibrium was attained in a shorter time, however, when pretreatment water was used.

It is sometimes argued that shaking may lead to the creation of fresh fracture surfaces, thus increasing the surface area in contact with the solution and hence perhaps causing an increase in the distribution ratio. It was therefore decided to investigate the effect of shaking rate by carrying out sorption experiments without shaking of the samples as well as shaking at a rate of $190 \mathrm{rpm}$. The results are shown in Fig. 5. It is seen that the rate of sorption is strongly affected by shaking. Saturation was reached after longer times for unshaken samples. The saturation $R_{D}$ values, however, do not differ significantly from one another. Thus no significant abrasion effect was observed, reflecting itself in higher $R_{D}$ values for samples that were shaken during sorption.

\section{Rate of sorption}

If sorption follows first order kinetics, plots of the logarithm of the activity remaining in the aqueous phase against time are expected to be linear in the pre-equilibrium region. Such linear dependence was not observed in our sorption studies (Fig. 6). In order to resolve two or more overlapping mechanisms and/or rate constants, the analogy with a mixture of independently decaying readioactive species was used (Tunall et al., 1974). The results are shown in Fig. 6. Two different first order rate constants, with corresponding initial activities, were obtained for all clay samples. The results of the analysis are given in Table 3 . In kaolinite, sorption was observed to take place predominantly with the slow mechanism. Since sorption in kaolinite takes place mostly on the surfaces and at the edges and with little sorption between the layers, the two mechanisms found can be ascribed to the sorption of $\mathrm{Ba}^{2+}$ ion on the surfaces and at the edges of kaolinite respectively. In the case of montmorillonite, the two mechanisms reflected by the two different rate constants probably represent adsorption on the surface and between layers respectively. The percentage of the two types of sorption are about equal as may be seen from the magnitudes of the $A^{0}$ values in Table 3. The chlorite-illite mixed clay was observed to sorb $\mathrm{Ba}^{2+}$ ion predominantly via the fast mechanism. The two rate constants observed in the sorption kinetic studies may also reflect the exchange of the $\mathrm{Ba}^{2+}$ ion with different bound cations such as $\mathrm{Na}^{+}, \mathrm{K}^{+}$, $\mathrm{Ca}^{2+}$, etc., rather than different mechanisms of sorption. In order to study this kind of sorption, experiments were carried out to measure the extent 


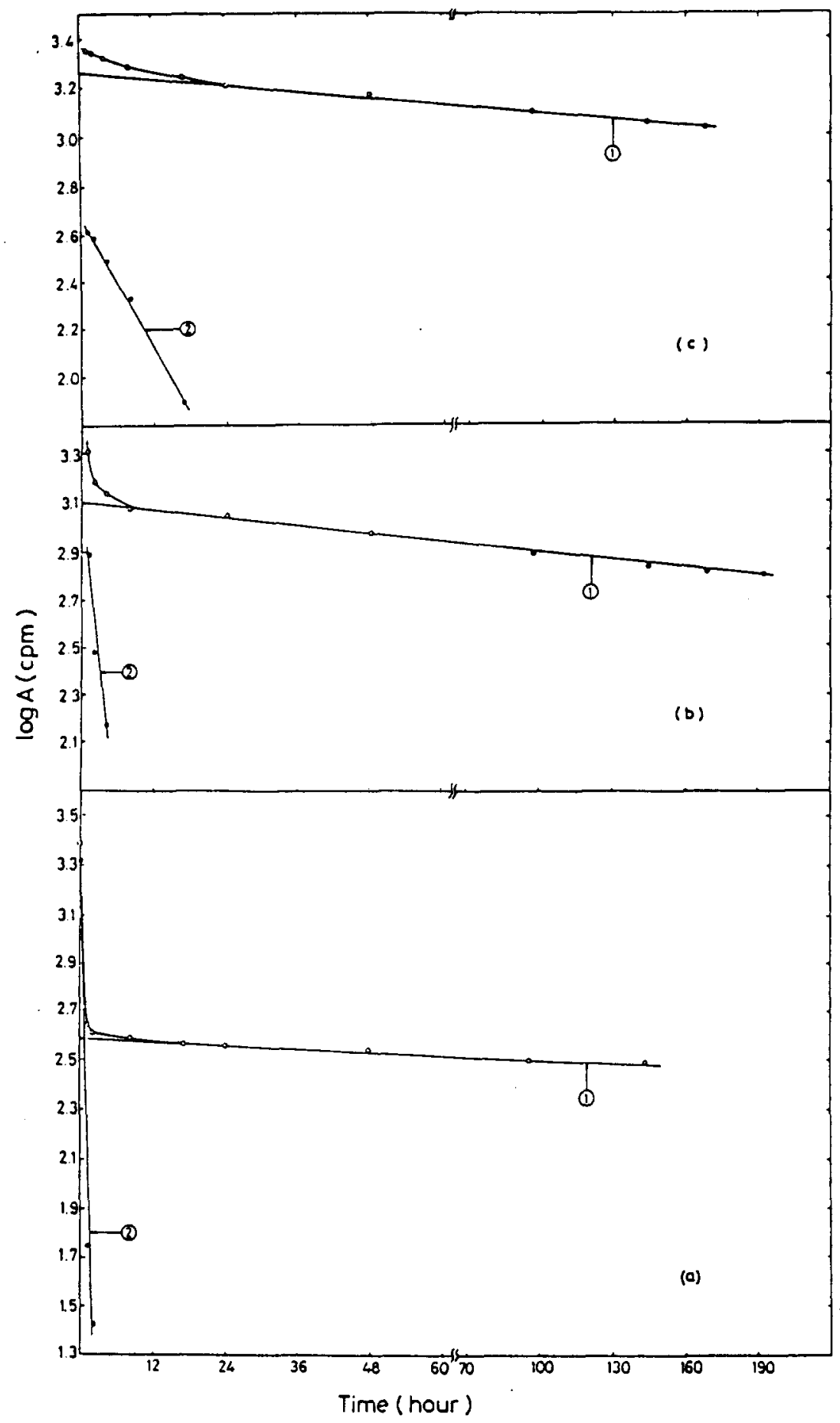

Fig. 6. Sorption kinetics. Plots of the logarithm of the activity remaining in the liquid phase as a function of time: (a) chlorite-illite mixed clay; (b) montmorillonite; (c) kaolinite. 
TABLE 3

Parameters Obtained from Curve Resolution

\begin{tabular}{lrrrr}
\hline \multicolumn{1}{c}{ Type of clay } & $A_{l}^{o}(\mathrm{cpm})$ & $A_{2}^{0}(\mathrm{cpm})$ & $k_{l}\left(h^{-1}\right)$ & $k_{2}\left(h^{-1}\right)$ \\
\hline Kaolinite & 1819.7 & $467 \cdot 7$ & $1.7 \times 10^{-3}$ & $4.5 \times 10^{-2}$ \\
Montmorillonite & 1258.9 & $1120 \cdot 0$ & $1.9 \times 10^{-3}$ & $2.3 \times 10^{-1}$ \\
Chlorite-illite & $380 \cdot 2$ & $2089 \cdot 3$ & $6.0 \times 10^{-4}$ & $9.5 \times 10^{-1}$ \\
\hline
\end{tabular}

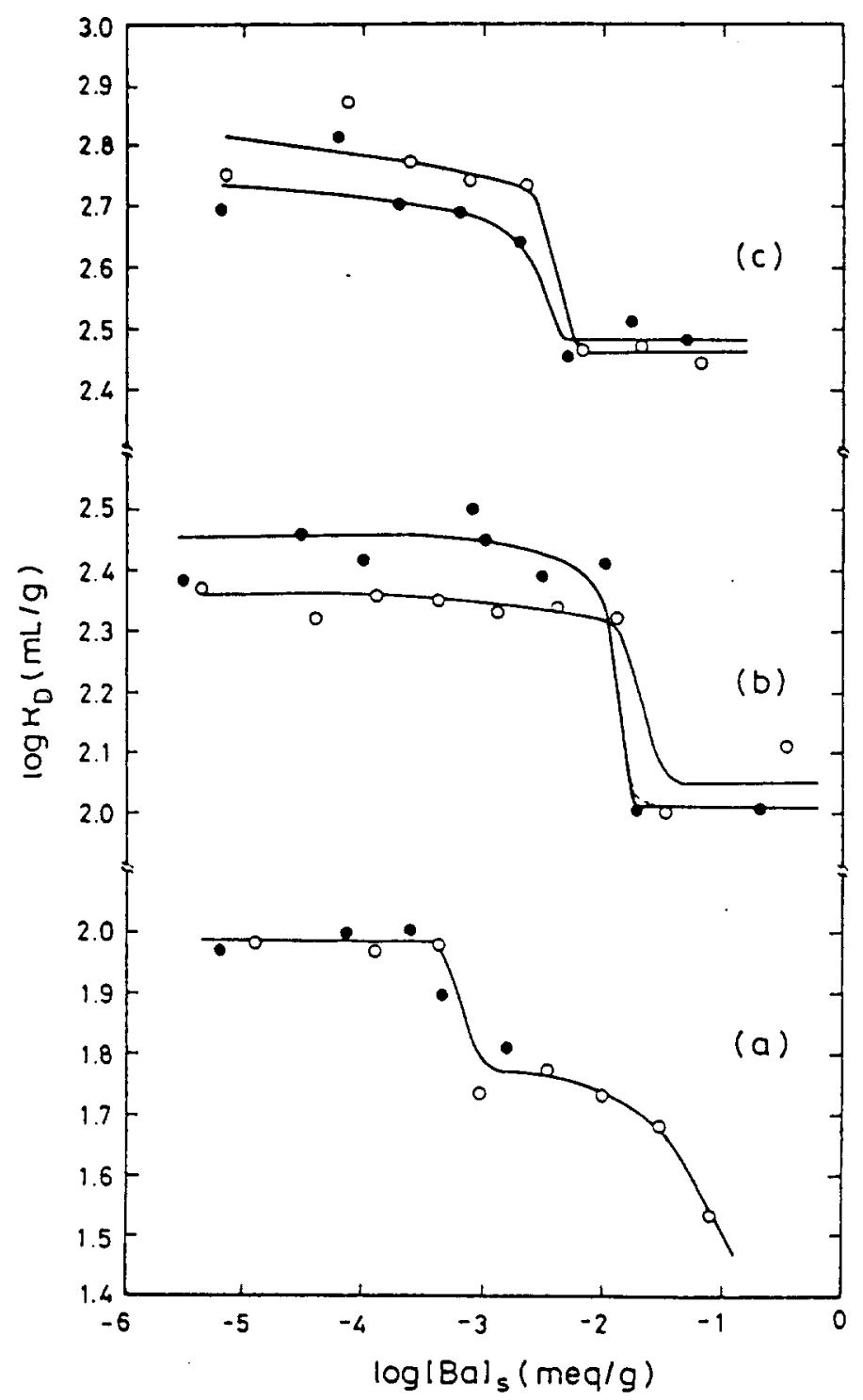

Fig. 7. Variation of $R_{D}$ as a function of $\mathrm{Ba}^{2+}$ ion loading. (a) kaolinite; (b) montmorillonite; (c) chlorite-illite. $\bigcirc$, Sorption; , desorption. 
of exchange of $\mathrm{Ba}^{2+}$ ion with $\mathrm{K}^{+}, \mathrm{Ca}^{2+}, \mathrm{Sr}^{2+}$ and $\mathrm{Al}^{3+}$ ions. The clay samples were first saturated with the respective cations given above and then sorption experiments with $\mathrm{Ba}^{2+}$ ion were carried out. The results indicate that $\mathrm{Ba}^{2+}$ exchanges most easily with $\mathrm{K}^{+}$followed by $\mathrm{Ca}^{2+}, \mathrm{Sr}^{2+}$ and $\mathrm{Al}^{3+}$ ions respectively.

\section{Influence of cation concentration on sorption}

The variation of the distribution ratio as a function of $\mathrm{Ba}^{2+}$ ion loading for three clay types is shown in Fig. 7. The standard deviation of $R_{D}$ values was less than $10 \%$ in all measurements. $R_{D}$ values are not expected to show any concentration dependence if they are true equilibrium constants. They were, however, found to vary with the $\mathrm{Ba}^{2+}$ ion concentration and to exhibit typical inverse S-shape curves suggesting the presence of different exchange sites, as was found in the kinetic studies. These exchange sites may be divided into three types (Sawhney, 1972; Brouwer et al., 1983; Evans et al., 1983): (1) sites on the planar surfaces. Sorption on kaolinite probably takes place at these sites where sorption is usually reversible; (2) sites at the edges of clay interlayers. These sites would be accessible only to cations having the same size and charge as the bound cations; (3) sites along the interlattice layers of collapsed or non-expanding clay minerals. Sorption of cations on these positions is mostly irreversible. Sorption of $\mathrm{Ba}^{2+}$ ion on montmorillonite and chlorite-illite mixture which was observed to be partly reversible seems to take place at type (1), (2) and (3) sites.

\section{Sorption isotherms}

The sorption isotherms are shown in Fig. 8. The isotherms were fitted to three different types of isotherm equations (NEA, 1983), namely Langmuir, Freundlich and Dubinin-Radushkevich. The parameters obtained in these fittings are given in Table 4. The sorption isotherms are described well by Freundlich and Dubinin-Radushkevich equations. The corresponding empirical relation has been obtained as

$$
R_{D}=K\left[\mathrm{Ba}^{2+}\right]^{N-1}
$$

from the Freundlich isotherm. Here, $K$ and $N$ are constants and $\left[\mathrm{Ba}^{2+}\right]=$ concentration of $\mathrm{Ba}^{2+}$ ion in the solution after sorption $(\mathrm{meq} / \mathrm{ml})$.

From the Dubinin-Radushkevich isotherm the equation

$$
R_{D}=\left[\mathrm{Ba}^{2+}\right]^{-1} X \exp \left\{-K\left[R T \ln \left(1+\left[\mathrm{Ba}^{2+}\right]^{-1}\right)^{2}\right]\right\}
$$

is obtained. Here, $X=$ cation exchange capacity per unit weight; $R=$ gas constant; $T=$ temperature (K); and $K=$ constant. 


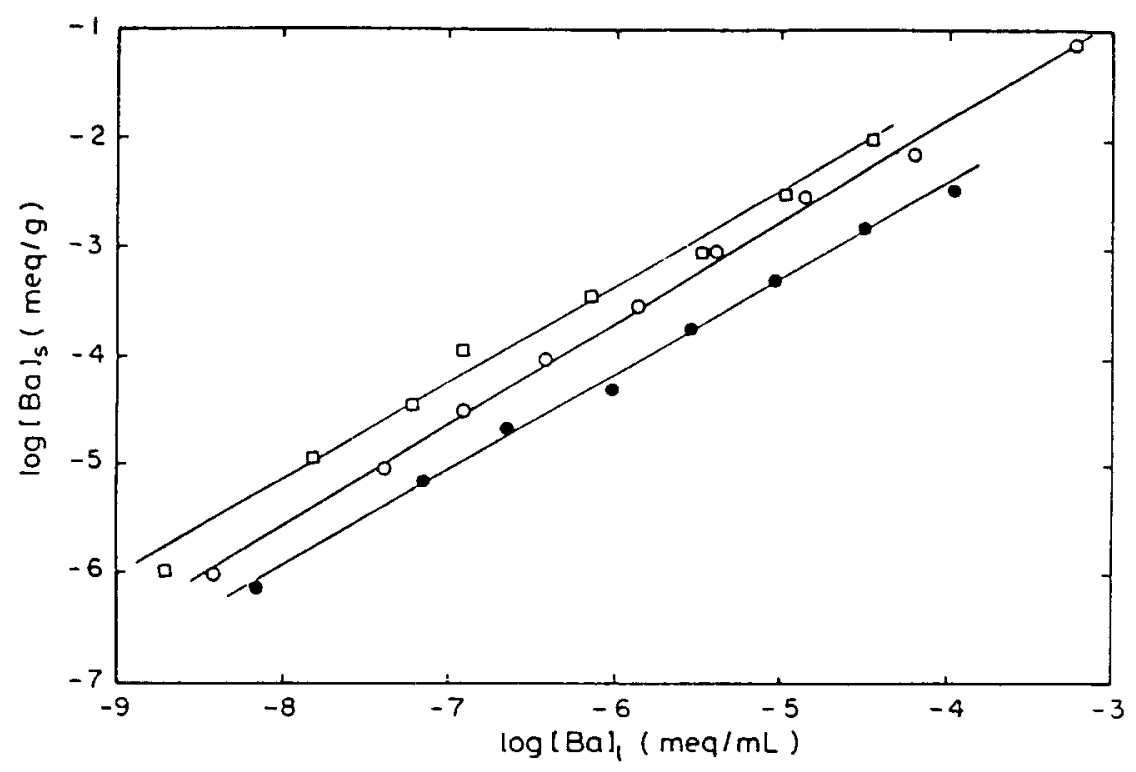

Fig. 8. Sorption isotherms of $\mathrm{Ba}^{2+}$ ion for the three clay samples: $\bullet$, kaolinite; $\bigcirc$, montmorillonite; $\square$, chlorite-illite mixed clay.

TABLE 4

Empirical Parameters Obtained from Fits to Various Isotherm Models

\begin{tabular}{lcccc}
\hline \multicolumn{1}{c}{ Isotherm model } & Parameters & Kaolinite & Montmorillonite & Chlorite-illite \\
\hline Langmuir & $X_{m}$ & 0.0021 & 0.076 & 0.0061 \\
& $1 / b$ & $2.25 \times 10^{-5}$ & $3.51 \times 10^{-4}$ & $8.32 \times 10^{-6}$ \\
& $C^{a}$ & 0.75 & 0.65 & 0.59 \\
Freundlich & $K$ & $7 \cdot 5$ & $86 \cdot 0$ & $98 \cdot 5$ \\
& $N$ & 0.84 & 0.94 & 0.89 \\
& $C^{a}$ & 1.00 & 1.00 & 1.00 \\
Dubinin-Radushkevich & $X$ & 0.054 & 0.22 & 0.16 \\
& $K$ & $6 \cdot 7 \times 10^{-5}$ & $6.0 \times 10^{-5}$ & $5.0 \times 10^{-5}$ \\
& $C^{a}$ & 1.00 & 0.99 & 0.99 \\
\hline
\end{tabular}

${ }^{a}$ Linear correlation coefficient. 
Experimental $R_{D}$ values were found to be in good agreement with those calculated using the empirical $R_{D}$ equations.

Differences in sorptivities of various size particles may be attributed to their different cation exchange capacities. If the sorption curves of different grain sizes are normalized with respect to their CECs, this difference is expected to decrease. For kaolinite, normalization removed the differences at low $\mathrm{Ba}^{2+}$ loadings, whereas in the high $\mathrm{Ba}^{2+}$ region, the curves were still different, indicating the presence of other factors. In the case of montmorillonite, normalization removed the differences at all $\mathrm{Ba}^{2+}$ loadings.

\section{The effect of $\mathrm{pH}$ and volume-mass ratio on sorption}

The influence of $\mathrm{pH}$ on $\mathrm{Ba}^{2+}$ ion sorption was studied in the $\mathrm{pH}$ range 3-11. The $\mathrm{pH}$ adjustment of the SGW was carried out using $\mathrm{NaOH}$ and $\mathrm{HNO}_{3}$. Sorption was observed to increase slightly with increase in $\mathrm{pH}$ for

TABLE 5

Steady State $R_{D}$ Values for $\mathrm{Ba}^{2+}$ Ion Sorption on Clays

\begin{tabular}{lc}
\hline \multicolumn{1}{c}{ Clay } & $R_{D}(\mathrm{~m} / \mathrm{g})$ \\
\hline Kaolinite & 127 \\
Montmorillonite & 238 \\
Chlorite-illite & 745 \\
\hline
\end{tabular}

kaolinite and chlorite-illite. For montmorillonite, $\mathrm{Ba}^{2+}$ sorption passed through a minimum around $\mathrm{pH} 8$ and increased considerably beyond that.

The influence of $v / m$ ratio on the sorption of $\mathrm{Ba}^{2+}$ ion on chlorite-illite was investigated in the range of $10 / 1$ to $200 / 1 \mathrm{ml} / \mathrm{g}$. The $R_{D}$ values slightly increased with increase in the volume-mass ratio within the range studied.

The highest observed steady state $R_{D}$ values for the sorption of $\mathrm{Ba}^{2+}$ ion on the three different clays are given in Table 5. The chlorite-illite mixed clay is apparently the best sorbent for $\mathrm{Ba}^{2+}$ ion, despite the higher CEC of montmorillonite. This is probably due to the organic content of chloriteillite mixed clay, which was determined (Jackson, 1958) to be about 5\%, and to other structural characteristics. Tamura \& Jacobs (1960), Jacobs \& Tamura (1961) and Sawhey (1964), observed similar behaviour for $\mathrm{Cs}^{+}$ ion sorption; non-expanding layer silicates, illite and micas sorbed more Cs from solution than did the expanding layer silicates, montmorillonite and vermiculite. 


\section{CONCLUSIONS}

There are significant differences in the sorption behaviour of the three clays studied. The highest $R_{D}$ values were obtained with chlorite-illite mixed clay followed by montmorillonite and kaolinite.

The distribution ratios tend to reach equilibrium in several days. Montmorillonite type clay reached equilibrium in the longest time. Generally, the distribution ratios were found to increase with decreasing particle size, reflecting mainly surface sorption processes.

Sorption was observed to take place in two stages each with a different rate constant in all clay types studied. In kaolinite, $\mathrm{Ba}^{2+}$ ion sorption occurred mainly on the surfaces and at the edges. In the case of chloriteillite mixed clay and montmorillonite, appreciable amounts of $\mathrm{Ba}^{2+}$ ion were sorbed between the layers. Sorption was reversible in kaolinite and partially reversible in chlorite-illite and montmorillonite.

Distribution ratios varied with the initial $\mathrm{Ba}^{2+}$ ion concentration, giving characteristic inverse S-shape curves. Sorption isotherms were best described by Freundlich and Dubinin-Radushkevich type equations.

Volume to mass ratio did not influence sorption of $\mathrm{Ba}^{2+}$ ion strongly. Increase in the $v / m$ ratio resulted in a slight increase in $R_{D}$ values.

Sorption of $\mathrm{Ba}^{2+}$ on chlorite-illite and kaolinite was observed to increase slightly with increase in $\mathrm{pH}$, whereas sorption of $\mathrm{Ba}^{2+}$ on montmorillonite depended strongly on $\mathrm{pH}$; increase in both acidity and basicity of the solution led to increase in $\mathrm{Ba}^{2+}$ ion sorption.

\section{ACKNOWLEDGMENT}

We gratefully acknowledge discussions with and the comments of Assoc. Prof. Dr Şahinde Demirci, the experimental help of Mehmet Türel and the skilful drawings of Semih Kolukısa.

\section{REFERENCES}

Berry, J. A., Hobley, J., Lane, S. A., Littleboy, A. K. \& Nash, J. M. (1988). The solubility and sorption of protactinium in the near field and farfield environments of a radioactive waste repository. Chemistry Division, Harwell Laboratory, UKAEA Report NSS/R122.

Brouwer, E., Baeyens, B., Maes, A. \& Cremers, A. (1983). Cesium and rubidium ion equilibria in illite clay. J. Phys. Chem., 87, 1213-19.

Carroll, D. (1959). Ion exchange in clays and other minerals. Bulletin of the Geological Society of America, 70, 749-80. 
Cremers, A., Elsen, A., De Preter, P. \& Maes, A. (1988). Quantitative analysis of radiocesium retention in soils. Nature, 335, 247-9.

Erten, H. N., Aksoyoğlu, \$., Hatipoğlu, S. \& Göktürk, H. (1988a). Sorption of cesium and strontium on montmorillonite and kaolinite. Radiochimica Acta, 44/45, 147-51.

Erten, H. N., Aksoyoğlu, Ş. \& Göktürk, H. (1988b). Sorption/desorption of Cs on clay and soil fractions from various regions of Turkey. The Science of the Total Environment, 69, 269-96.

Evans, W. D., Alberts, J. J. \& Clark, R. A. (1983). Reversible ion-exchange fixation of cesium-137 leading to mobilization from reservoir sediments. Geochim. Cosmochim. Acta, 47, 1041-9.

Grütter, A., Von Gunten, H. R. \& Rössler, E. (1986). Sorption, desorption and ion exchange of cesium on chlorite. Clays and Clay Minerals, 34, 677-80.

Jackson, M. L. (1958). Soil chemical analysis. Prentice-Hall Inc, New York.

Jacobs, D. G. \& Tamura, T. (1961). The mechanism of ion fixation using radio-isotope techniques. In Transactions of the 7th International Congress on Soil Science, Madison, 1960, Vol. 2, International Society of Soil Science. Elsevier, Amsterdam, pp. 206-14.

Loomis, A. G. (1938). Grain size of whiteware clays as determined by the Andreasen pipette. Am. Cer. Soc. J., 21(11), 393.

NEA Workshop Report (1983). Sorption, modelling and measurement for nuclear waste disposal studies. Report of Co-ordinating Group on Geological Disposal of Radioactive Wastes, 6-7 June, Paris.

Norton, F. H. \& Speil, S. (1938). The measurement of particle sizes in clays. Am. Cer. Soc. J., $21(3), 89-97$.

Sawhney, B. L. (1964). Sorption and fixation of microquantities of Cs by clay minerals: effect of saturating cations. Soil Sci. Soc. Proc., 24, 183-6.

Sawhney, B. L. (1972). Selective sorption and fixation of cations by clay minerals: a review. Clays and Clay Minerals, 20, 93-100.

Searle, P. L. (1986). The measurement of soil cation exchange properties using the single extraction, silver thiourea method. Aust. J. Soil. Res., 24, 193-200.

Tamura, T. \& Jacobs, D. G. (1960). Structural implications in cesium sorption. Health Physics, 2, 391-8.

Torstenfelt, B. (1986). Migration of the fission products, strontium, technetium, iodine and cesium in clay. Radiochimica Acta, 39, 97-104.

Torstenfelt, B., Andresson, K. \& Allard, B. (1981). Sorption of Sr and Cs on rocks and minerals. Sweden National Council for Radioactive Waste Report. Report Prav. 4.29.

Tunalı, N. K., Erten, H. N., Kırıkoğlu, S. \& Gümüş, S. (1974). Solvent extraction behaviour of iodine and bromine in aqueous-organic systems. Journal of Radioanalytical Chemistry, 49, 225-37. 